\title{
First Year Undergraduate Mathematics Students Error Analysis on Solving Rational Inequality
}

\author{
Mohammad Agung ${ }^{1, *}$ Indriati Hidayah ${ }^{1}$ Trianingsih Lestari $^{1}$ Lucky Oktoviana $^{1}$ \\ Dahliatul Hasanah ${ }^{1}$
}

\author{
${ }^{1}$ Department of Mathematics, FMIPA, Universitas Negeri Malang \\ ${ }^{*}$ Corresponding author. Email: mohammad.agung.fmipa@um.ac.id
}

\begin{abstract}
Solving a rational inequalities is difficult for mathematics students. Many of them make a mistake when solving such problem. This research aimed to investigate and categorize a first year mathematics undergraduate student error when solving rational inequalities problem. The data were obtained from 75 students taking the course introduction to algebra, through anlysis of students response to the items of the quiz. The result showed that many students had mistake of type errorrs in inequality rules. Most of them are solving the rational inequalities by treating it as a rational equation. This mistake happen because they misunderstand about the rule of inequality while they are performing multiplication. The other mistake is of type error in writing the solution. The students didn't use number line so that leads to incorrect solution set.
\end{abstract}

Keywords: rational inequality, students' error, error analysis.

\section{INTRODUCTION}

Inequality is two or more algebraic expression connected using symbols $<$, >, $\leq$, or $\geq$. Solving an inequality means finding all possible value(s) of variable that make a correct statement. In higher education, inequalities are considered as an important mathematical topic as a prerequisite for many subjects such as algebra, trigonometry and analytic geometry [1]. Hence it is essential for undergraduate mathematics students to comprehend this topic. However, in facts many students have errors in solving inequalities. Research conducted by Blanco and Garrote [2] indicated that students still have two major difficulties dealing with inequality, namely arithmetic, and the absence of meaning. While El-khateeb [1] argued that the greatest common errors did by students when solving inequality is basic algebraic operation and deletion. In the other hand, based on our teaching experience, most students still have poor calculation, wrongly determine the solution set, and misunderstand the rule of solving inequality. These errors affect students' work on other material, such as function, and optimization problem.

The errors did by students were not happened by chance, but rather as an impact of students' conceptual framework which is based on their previous knowledge
[2]. Another possible causes for this error is that students have a weak background in elementary mathematics [3]. Moreover, transision phase from high school learning to higher education learning is suspected to be the main reason why mathematics students in Universitas Negeri Malang still have difficulties in solving inequality.

One of interesting topics in inequality is rational inequality. Rational inequality is an inequality involving one or more rational expressions. There are many issues faced by students when dealing with this kind of inequality, for example is doing cross-multiplication. The students usually treat rational inequality like rational equation. This error could give a fatal mistake to the other concept, such as determining domain of a function involving rational. For example, in determining the natural domain of function $f(x)=\sqrt{\frac{x-1}{2 x+3}-2}$, students are required to solve the inequality $\frac{x-1}{2 x+3}-2 \geq 0$. Some students attempt to solve this inequality by adding both sides with 2 and then do cross multiplication. This attempt of course leads to wrong domain of the function $f(x)$. This kind of error not only happen in first year students but also can be found in sophomore even in fourth year students. 
Researches on inequality have been conducted by many researchers, but it is relatively less researches ng on rational inequality. The study conducted by Pratiwi and Rosjanuardi [4] shows that many students incorrectly find the solution of rational inequality because students did not use the number line to find the desired solutions. It means that many students did not have good understanding about the rule in solving inequality. Hence investigation and classification the errors did by students when solving rational inequality is a crucial need to overcome students' error itself.

In the light of need of investigation and classification the errors did by students when solving rational inequality, this research is aimed to classify those errors. Through the classification results, it is expected to be a reference for the mathematics academic community especially for lecturers to choose a suitable teaching design when dealing such errors.

\section{METHODS}

\subsection{Participants}

The participants of this research were 75 undergraduate students in first semester who take Introduction to Algebra course in Universitas Negeri Malang, Indonesia.

\subsection{Instruments}

Instruments used in this study were two questions about rational inequality. These questions were built for the purpose of the appearance of expected error in students work. The problems consist of two questions of essay type.

\subsection{Data and Study Procedure}

The purpose of the study is classifying the errors that occur in students work to some classes of error. From 75 respondents there are three types of error considered in this research, that are: error in algebraic operation, error in applying inequality rule, and error in determining solution set. For the first and the last type, we take one subject for each type, and two subjects for the second type, and analyse the answers in details. The subjects taken for second type are different from the other two types, because the number of students who did this type of error is almost twice as many as the other types, and from the second type, there are two major different kind of mistakes did by the students.

\section{RESULTS AND DISCUSSION}

The purpose of the study is classifying the errors that occur in students work to some classes of error. From 75 respondents there are three types of error considered in this research, that are: error in algebraic operation, error in applying inequality rule, and error in determining solution set. For the first and the last type, we take one subject for each type, and two subjects for the second type, and analyse the answers in details. The subjects taken for second type are different from the other two types, because the number of students who did this type of error is almost twice as many as the other types, and from the second type, there are two major different kind of mistakes did by the students.

\subsection{Error in Algebraic Operations}

This type of error is demonstrated when some students subtract two rational expression. Some students forcing to do the subtraction even though the denominators are not equal. (Figure 1)

\subsection{Error in Applying Inequality Rule}

This type of error is demonstrated when some students treat rational inequality as a rational equation, hence they directly use cross-multiplication instead of equating the denominator. (Figure 2) There is also case when students were not using the number line to determine the solution after doing algebraic operations. (Figure 3)

\begin{tabular}{l}
$\frac{1}{x}>x-2$ \\
$\frac{1}{x}-x-2>0$ \\
$\frac{1-x-2}{x}>0$ \\
$\frac{-x-1}{x}>0$ \\
$\Rightarrow \frac{-x-1>0}{x}>-1$ \\
$\begin{array}{l}\rightarrow x=0 \\
\Rightarrow\end{array}$ \\
\hline
\end{tabular}

Figure 1 Student error in algebraic operation

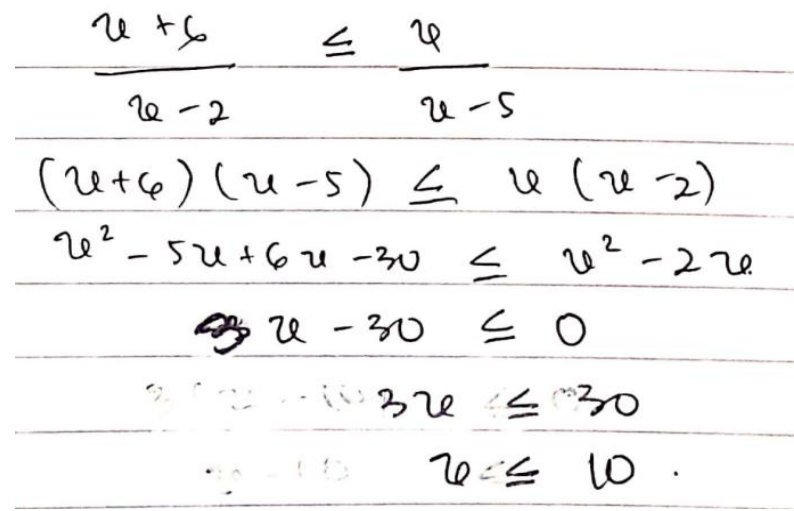

Figure 2 Student using cross multiplication 


\subsection{Error in Determining the Solution Set}

The last type of error is actually minor compared to the other two errors, but surprisingly appear more frequently than the first error. This error is demonstrated when some students wrongly determine the area in the number line that indicates the desired solution. (Figure 4) This happen because students doing some miscalculation when substituting some number in certain region in number line to the inequality, to check whether the region is part of the desire solution or not.

\subsection{Discussion}

After classifying students' error into these three types of error, we also analyse the ratio of occurrence each type of error. The purpose of this is to determine which type of error that occur the most.

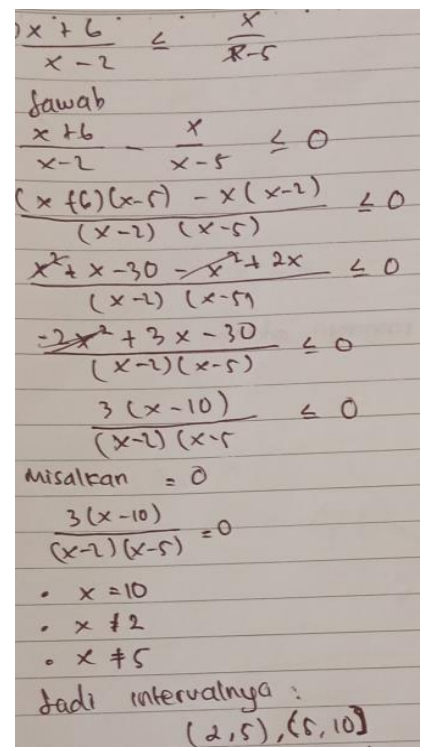

Figure 3 Student didn't use number line

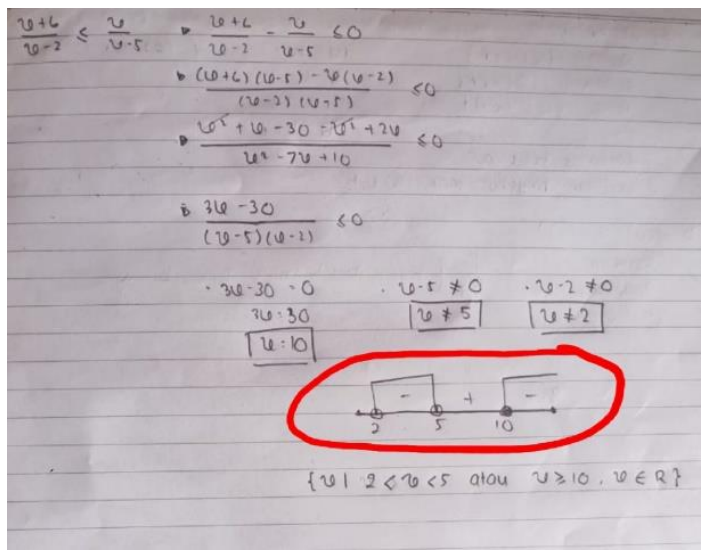

Figure 4 Student error in determining the solution set
This is expected to help lecturer to decide suitable treatment for their students in solving rational inequality. The ratios are given in the Table 1

From Table 1, error in applying inequality rule is the one that is likely happen when student solve a rational inequality. Among 25 students who did this error, 17 students are using cross multiplication to solve the given rational inequality. As mentioned above, this is happened because students treat rational inequality as a rational equation. For instance, when students are asked a question such as if $\frac{a}{b}<\frac{c}{d}$, where $a, b, c, d$ are real numbers with $b, d \neq 0$, can we conclude that $a d<b c$, most of them say yes. This proves that the students' errors in solving rational inequality are not happen by chance, but rather as the impact of their previous knowledge.

An error in doing algebraic operations, even its minor compared to the other two errors, still becomes a threat to students work in solving rational inequality. Students failure on doing algebraic operations leads to an incorrect procedure in solving an inequality [5]. This is, again, because of their previous knowledge on adding or subtracting two fractions. A common error occurred when students adding or subtracting two algebraic fractions is that the students are multiply the denominators instead of finding its least common multiple [6].

Errors that happened when students solve rational inequalities need to be considered as a problem in teaching and learning mathematics. Our teaching experience has allowed us to observe the difficulties that students have, and the errors they make, when they are studying inequalities [2]. Finding what might be some of the causes and what suitable learning design that can reduce the possibilities of re-occurrence of the error that happened today, is one of lecturers' duty.

The result we achieved in this study is analogous with the result achieved by Priyani and Ekawati [7]. In their study about error analysis of mathematical problems on TIMSS, they classify error made by students in three categories, that are conceptual error, operational error, and principal error. Conceptual error occurs when students are not able to apply the concept. This is analogous to our error in applying inequality rule, which lead to a noncomplete solution of the inequality. Operational error happened when students are not able to do the calculation. This is analogous to our error in doing algebraic operations. This kind of error is a common to many materials in mathematics involving algebraic expressions. Principal error occurs when students are not able to answer the final answer. This is analogous with 
Table 1 Ratios of occurrence each type of error

\begin{tabular}{|l|l|l|}
\hline Type of Error & Frequency of Occurrence & Percentage \\
\hline Error in algebraic operations & 11 & $22 \%$ \\
\hline Error in applying inequality rule & 25 & $50 \%$ \\
\hline Error in determine the solution set & 14 & $28 \%$ \\
\hline Total & 50 & \multicolumn{2}{|l}{} \\
\cline { 1 - 2 } &
\end{tabular}

our error in determining the solution set, which is caused by some miscalculation.

\section{CONCLUSION}

As conclusion, it was found that among 75 first year mathematics students in universitas negeri malang, 50 students are doing errors when solving rational inequality problem. Among 50 students doing error, 22\% students doing error in algebraic operations, $50 \%$ doing error in applying inequality rule, and $28 \%$ students doing error in determine the solution set. According to this result, it is necessary to design a teaching and learning that can wiped out these errors. The design should have more concern in dealing with the error in applying inequality rule, such as doing cross-multiplication. The learning design is expected to prevent students doing this kind of error in their future study.

\section{AUTHORS' CONTRIBUTIONS}

The authors contribution to the paper as follows: study conception and design: Mohammad Agung, Indriati Hidayah; data collection: Mohammad Agung, Dahliatul Hasanah; analysis and interpretation of results: Mohammad Agung, Indriati Hidayah, Trianingsih Lestari, Lucky Oktoviana; draft manuscript preparation: Dahliatul Hasanah, Trianingsih Lestari, Lucky Oktoviana. All authors reviewed the results and approved the final version of the manuscript.

\section{ACKNOWLEDGMENTS}

This work is funded by PNBP Universitas Negeri Malang. The Authors wish to express their gratitude to anonymous referees for their helpful comments and suggestions.

\section{REFERENCES}

[1] M. M. A. El-khateeb, "Errors Analysis of Solving Linear Inequalities among the Preparatory Year Students at King Saud University .," J. Educ. Pract., vol. 7, no. 12, pp. 124-133, 2016, [Online]. Available: www.iiste.org.

[2] L. J. Blanco and M. Garrote, "Difficulties in learning inequalities in students of the first year of pre-university education in Spain," Eurasia J. Math. Sci. Technol. Educ., vol. 3, no. 3, pp. 221-229, 2007, doi: 10.12973/ejmste/75401.

[3] B. M. Shalash, "Students 'Misconceptions and Mistakes in General Mathematics Course Among Al-Quds Open University Students," 2019, [Online]. Available: http://dspace.up.edu.ps/xmlui/handle/1234567 $89 / 406$.

[4] Y. Pratiwi and R. Rosjanuardi, "Error Analysis in Solving the Rational and Irrational Inequalities," 2020, doi: 10.4108/eai.12-102019.2296414.

[5] M. Taqiyuddin, E. Sumiaty, and A. Jupri, "Analysis of junior high school students' attempt to solve a linear inequality problem," AIP Conf. Proc., vol. 1868, no. August, 2017, doi: 10.1063/1.4995160.

[6] Z. B. Dhlamini and I. Kibirige, "Grade 9 learners' errors and misconceptions in addition of fractions," Mediterr. J. Soc. Sci., vol. 5, no. 8, pp. 236-244, 2014, doi: 10.5901/mjss.2014.v5n8p236.

[7] H. A. Priyani and R. Ekawati, "Error analysis of mathematical problems on TIMSS: A case of Indonesian secondary students," IOP Conf. Ser. Mater. Sci. Eng., vol. 296, no. 1, pp. 0-6, 2018, doi: 10.1088/1757-899X/296/1/012010. 